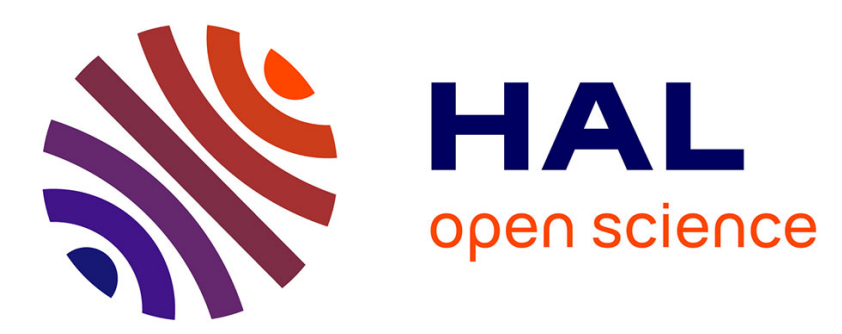

\title{
Continuous flow solar desorption of CO2 from aqueous amines
}

Zachary S. Campbell, Suyong Han, Samuel Marre, Milad Abolhasani

\section{To cite this version:}

Zachary S. Campbell, Suyong Han, Samuel Marre, Milad Abolhasani. Continuous flow solar desorption of CO2 from aqueous amines. ACS Sustainable Chemistry \& Engineering, 2021, 9 (6), pp.2570-2579. 10.1021/acssuschemeng.0c08600 . hal-03142055

\section{HAL Id: hal-03142055 \\ https://hal.science/hal-03142055}

Submitted on 2 Mar 2021

HAL is a multi-disciplinary open access archive for the deposit and dissemination of scientific research documents, whether they are published or not. The documents may come from teaching and research institutions in France or abroad, or from public or private research centers.
L'archive ouverte pluridisciplinaire HAL, est destinée au dépôt et à la diffusion de documents scientifiques de niveau recherche, publiés ou non, émanant des établissements d'enseignement et de recherche français ou étrangers, des laboratoires publics ou privés. 
This document is confidential and is proprietary to the American Chemical Society and its authors. Do not copy or disclose without written permission. If you have received this item in error, notify the sender and delete all copies.

\section{Energy-Efficient Continuous Solar Desorption of CO2 from Aqueous Amines}

\begin{tabular}{|c|c|}
\hline Journal: & ACS Applied Materials \& Interfaces \\
\hline Manuscript ID & am-2020-20822x \\
\hline Manuscript Type: & Article \\
\hline $\begin{array}{r}\text { Date Submitted by the } \\
\text { Author: }\end{array}$ & 22-Nov-2020 \\
\hline Complete List of Authors: & $\begin{array}{l}\text { Campbell, Zachary; North Carolina State University College of } \\
\text { Engineering, Department of Chemical and Biomolecular Engineering } \\
\text { Han, Suyong; North Carolina State University, Chemical and } \\
\text { Biomolecular Engineering } \\
\text { MARRE, Samuel; Institute of Condensed Matter Chemistry of Bordeaux, } \\
\text { Supercritical Fluids } \\
\text { Abolhasani, Milad; North Carolina State University, Chemical and } \\
\text { Biomolecular Engineering }\end{array}$ \\
\hline
\end{tabular}

\section{SCHOLARONE \\ Manuscripts}




\title{
Energy-Efficient Continuous Solar Desorption of
}

\section{$\mathrm{CO}_{2}$ from Aqueous Amines}

Zachary S. Campbell, ${ }^{1}$ Suyong Han, ${ }^{1}$ Samuel Marre, ${ }^{2 *}$ and Milad Abolhasani ${ }^{1 *}$.

${ }^{1}$ Department of Chemical and Biomolecular Engineering, North Carolina State University, Raleigh, NC USA

${ }^{2}$ CNRS, Univ. Bordeaux, Bordeaux INP, ICMCB, UMR 5026, F-33600 Pessac, France

$\mathrm{CO}_{2}$ Capture; Solar Desorption; Composite Photothermal Microparticles; Microfluidics

\begin{abstract}
Recovery of captured carbon dioxide $\left(\mathrm{CO}_{2}\right)$ is considered the most energy-intensive stage of postcombustion $\mathrm{CO}_{2}$ capture strategies by aqueous amines. In response, an optically transparent, flow reactor with continuous in operando $\mathrm{CO}_{2}$ collection using light-absorbing, graphite-titania composite microparticles is developed for energy-efficient solar desorption of $\mathrm{CO}_{2}$ from saturated aqueous amine absorbents. The synthesized graphite-titania composite microparticles are demonstrated to be a more effective packing material for the continuous $\mathrm{CO}_{2}$ solar desorption in the packed-bed flow reactor compared to other candidates, including titania and carbon black. The effect of continuous and discrete parameters, including irradiance, residence time, amine concentration, and amine chemical structure on the efficiency of the solar-enabled $\mathrm{CO}_{2}$ desorption
\end{abstract}


using the developed continuous flow strategy with the graphite-titania composite microparticle packing are studied in detail. Furthermore, the potential for implementation of a control strategy by adjusting the aqueous amine stream flow rate to achieve constant $\mathrm{CO}_{2}$ desorption efficiency with a dynamic solar irradiance is discussed. Finally, the continuous $\mathrm{CO}_{2}$ desorption stability over an extended period of time $(12 \mathrm{~h})$ is examined with an average single-pass efficiency of $64 \%$.

\section{INTRODUCTION}

Human activities after the second industrial revolution in the early $19^{\text {th }}$ century have resulted in an increase of the atmospheric carbon dioxide $\left(\mathrm{CO}_{2}\right)$ concentration from 280 to above 400 ppm over the past 110 years, primarily due to the constant growth of population and everincreasing worldwide energy demand. ${ }^{1,2}$ The unmitigated emission of $\mathrm{CO}_{2}$ and other greenhouse gases is causing an unprecedented rapid rise in average global temperatures and an overall irreversible change in climate. ${ }^{3-5}$ As the concentration of atmospheric $\mathrm{CO}_{2}$ continues to climb, ${ }^{4}$ it is imperative to develop and implement strategies for energy-efficient $\mathrm{CO}_{2}$ capture, sequestration, and utilization (CCUS). ${ }^{6}$ Current shortcomings of mitigation efforts concerning $\mathrm{CO}_{2}$ emission, including the high energy cost of $\mathrm{CO}_{2}$ capture and recovery from stationary sources (e.g., power plants) which can represent up to $80 \%$ of the associated CCUS cost, and the comparatively low efficiency of renewable and sustainable energy alternatives (e.g., solar cells), ${ }^{7}$ have inhibited widespread implementation of these technologies in the energy sector.

Over the last three decades, numerous techniques have been developed for selective $\mathrm{CO}_{2}$ capture, including adsorption,,${ }^{8,9}$ absorption, ${ }^{10,11}$ and membrane separation, ${ }^{12,13}$ among others. However, of these strategies, absorption with aqueous amines (e.g., monoethanolamine, MEA) is one of the most widely utilized strategies for $\mathrm{CO}_{2}$ capture in applications ranging from natural gas 
sweetening ${ }^{11}$ to post-combustion $\mathrm{CO}_{2}$ removal. ${ }^{14}$ Despite groundbreaking advancements in $\mathrm{CO}_{2}$ capture with aqueous amines, this technique suffers from a high energy penalty for the recovery of the captured $\mathrm{CO}_{2}$. The most substantial hurdle to widespread implementation as a postcombustion capture strategy is the energy input necessary to desorb the captured $\mathrm{CO}_{2}$ from the aqueous amine solution so it may be reused, requiring regeneration temperatures around $120^{\circ} \mathrm{C} .{ }^{15}$ This is further complicated by the massive quantity of absorbent necessary to fully extract the $\mathrm{CO}_{2}$ from stationary sources of $\mathrm{CO}_{2}$ and the requisite absorbent replacement due to degradation. This limitation, along with rising global energy demands, necessitates the development of more efficient physical and chemical absorbents for $\mathrm{CO}_{2}$ capture from stationary sources, as well as a more sustainable strategy for its recovery. ${ }^{16}$ Among different energy-efficient $\mathrm{CO}_{2}$ desorption strategies, solar energy is considered among the most promising candidates as a readily available source of energy to heat the solution and aid $\mathrm{CO}_{2}$ desorption. This concept has recently been demonstrated by the addition of carbon black nanoparticles to the MEA solution, which have been shown to effectively absorb light resulting in bulk heating of the solution followed by $\mathrm{CO}_{2}$ desorption. ${ }^{17}$ While this strategy has been demonstrated to be effective for its intended purpose, it raises additional technological challenges since the addition of particulates to the capture solution has the potential to present problems for the conventional large scale centrifugal pumps that would likely be used in such an application. Furthermore, batch techniques are prone to additional complications, including reduced light penetration $(\sim 1 \mathrm{~mm}),{ }^{18,19}$ particle settling with insufficient agitation, excessively long $\mathrm{CO}_{2}$ desorption timescales, and the presence of large concentration and temperature gradients in batch reactors. In particular, large diffusion length scales associated with conventional macroscale characterization techniques make the development of alternative $\mathrm{CO}_{2}$ recovery routes challenging and time-consuming. For this reason, it is intriguing to consider 
a continuous flow strategy utilizing light-absorbing microparticles for solar heating of $\mathrm{CO}_{2}$ saturated aqueous amine solutions to achieve continuous, energy-efficient $\mathrm{CO}_{2}$ recovery while removing costs associated with separating the recovered aqueous amine and light-absorbing particles.

Recently, microfluidic strategies have emerged as a promising tool for fundamental and exploratory studies of gas-liquid reactions, ${ }^{20-22}$ including accelerated exploration of $\mathrm{CO}_{2}$ capture and utilization processes. ${ }^{23-31}$ Advantages of microscale strategies include enhanced rates of heat and mass transfer, small (micro- to nano-liter) reagent volumes, controlled variation of reagent concentrations in a high-throughput manner, reproducibility, and the integration of analytical tools with microfluidic reactors for real-time process characterization and optimization. ${ }^{21,32,33}$ Additionally, a continuous photothermal heating strategy is best applied using micro/milli-fluidic reactors due to their excellent light transmittance, as the use of small scale channels $(<1 \mathrm{~mm})$ results in significantly higher light absorption by the light-absorbing particles than conventional batch reactors. $^{18}$

Here, we present a microscale fluidic strategy for continuous solar-driven desorption and in operando recovery of captured $\mathrm{CO}_{2}$ from aqueous amine solutions. By utilizing a membranebased flow reactor, ${ }^{27,34}$ the desorbed $\mathrm{CO}_{2}$ can be continuously separated from the aqueous amine solution, in-situ, as it is released in the flow reactor, while the liquid phase continues through the packed-bed region. Using the developed continuous flow reactor, we demonstrate a single-pass $\mathrm{CO}_{2}$ desorption efficiency of $64 \%$ via illumination of the reactor with a light source selected to emulate a solar concentrator. 


\section{EXPERIMENTAL}

Materials. Monoethanolamine ( $\geq 99.0 \%$, ACS Reagent), titanium n-butoxide (97\%, reagent grade), toluene ( $\geq 99.5 \%$, ACS reagent), ethoxylated trimethylolpropane triacrylate $\left(\mathrm{M}_{\mathrm{n}} \sim 428\right)$, and diphenyl(2,4,6-trimethylbenzoyl)phosphine oxide (97\%) were purchased from Sigma Aldrich. Carbon black was purchased from Cabot. Nitrogen $\left(\mathrm{N}_{2}\right.$, grade 5.0) and $\mathrm{CO}_{2}$ (industrial grade) were purchased from Messer. The graphite-titania $\left(\mathrm{G}-\mathrm{TiO}_{2}\right.$ composite) microspheres used to pack the flow reactor were synthesized using a flow-focusing microreactor presented previously by our group. ${ }^{35-38}$ However, rather than annealing the microparticles at $500{ }^{\circ} \mathrm{C}$, the in-flow synthesized microparticles were calcined under ambient atmosphere at $400{ }^{\circ} \mathrm{C}$, which resulted in the formation of $\mathrm{G}_{-} \mathrm{TiO}_{2}$ composite microparticles. Deionized (DI) water $(18 \mathrm{M} \Omega-\mathrm{cm})$ was generated using the on-site facility. All chemicals were used as received.

Microfluidic Platform. A schematic of the developed microfluidic platform utilizing a tube-intube flow reactor configuration is shown in Figure 1. The microreactor was constructed by attaching stainless steel T-junctions (1/8 in, Swagelok) to fluorinated ethylene propylene (FEP) tubing (outer diameter (OD): $\quad 1 / 8$ in; inner diameter (ID): $1 / 16 \quad$ in, IDEX Health \& Science).

Stainless steel reducers $(1 / 8$ in to $1 / 16$ in, Swagelok) were then inserted into each Tjunction, in line with the

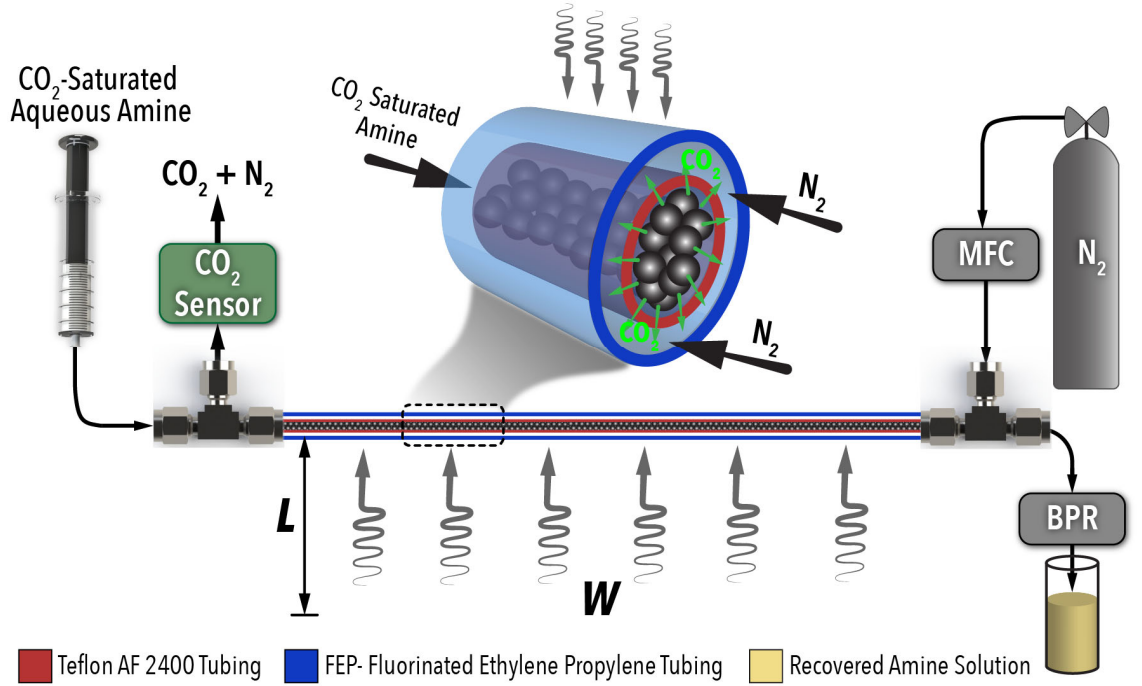

Figure 1. Schematic illustration of the developed flow chemistry platform utilizing a tubein-tube packed bed microreactor for continuous solar-enabled $\mathrm{CO}_{2}$ desorption from aqueous amines. 
FEP tubing. Next, a tubular gas-permeable membrane (Teflon AF 2400 tubing, OD: 0.04 in, ID: 0.032 in, Biogeneral) was inserted through the reducers, T-junctions, and FEP tubing. A Teflon frit (PEEK, $2 \mu \mathrm{m}$ pore size, IDEX Health $\&$ Science) was used to ensure the packed particles stay inside the tube-in-tube flow reactor. After closing one end of the Teflon AF 2400 tubing, lightabsorbing microparticles were introduced into the inner (Teflon AF 2400) tube until the section between the T-junctions was completely packed with microparticles. Bright field images of the packed-bed flow reactor are presented in Figure S1. The open end of the Teflon AF2400 was then sheathed with a $4 \mathrm{~cm}$ segment of $1 / 16$ in OD, FEP tubing and tightened in place with $1 / 16$ in Swagelok fittings, while the other end was capped with a Teflon frit (PEEK, $2 \mu \mathrm{m}$ pore size, IDEX Health \& Science) and needle valve. One needle valve was attached to the 1/16 in OD, FEP tubing with a Luer-lock fitting (PEEK, IDEX Health \& Science), while another 1/16 in OD FEP tubing was attached to the opposite end of the flow reactor and fed into the collection beaker. The $\mathrm{CO}_{2}$ saturated aqueous amine solution was continuously fed to the gas-permeable inner tube using a 5 $\mathrm{mL}$ syringe (gas-tight, SGE) and a syringe pump (KD Scientific, KDS-100-CE).

The perpendicular ports of the stainless steel T-junctions were attached to an FEP tubing (OD:1/8 in; ID: $1 / 16$ in) to enable gas flow through the outer annulus of the tube-in-tube flow reactor. The gas inlet, positioned in counter-flow arrangement with respect to the liquid inlet stream, was connected to a $\mathrm{N}_{2}$ (carrier gas) mass flow controller (MFC) (Brooks), while the gas stream outlet was connected to a $\mathrm{CO}_{2}$ sensor (Gas Sensing Solutions, SPRINTIR-WF-20). A light source (SuperPlant E40 50x40 Stucco diffuser, SuperPlant MH 600W bulb, and Lumatek Adjustable Electronic Ballast) with tunable power (250 W to $600 \mathrm{~W})$, was placed at the desired distance $(H)$ over the tube-in-tube flow reactor using a ring stand. The lamp emission spectrum can be found in Figure S2. Following preliminary experiments, the feed tube was partially packed 
with the light-absorbing microparticles and folded aluminum strips were added to serve as solar concentrators and enhance total irradiance.

Flow Reactor Operation. Solar-enabled $\mathrm{CO}_{2}$ desorption experiments were started by filling the packed bed flow reactor with DI water. The syringe was then filled with the desired amine solution saturated with $\mathrm{CO}_{2}$ (prepared under inert atmosphere in a glove box, saturated by bubbling $\mathrm{CO}_{2}$ through the solution until it returned to near ambient temperature). Next, the syringe pump was set at a high flow rate until the amine solution reached the preheating section of the flow reactor. The light source was then turned on, the liquid feed rate was set to achieve the desired residence time, $t_{\mathrm{R}}$, and the $\mathrm{N}_{2}$ flow rate was set to $3 \mathrm{~mL} / \mathrm{min}$. Over the course of each experiment, $\mathrm{CO}_{2}$ concentration in the gas phase (i.e., $\mathrm{CO}_{2}$ and the carrier gas) was monitored in real time and was allowed to reach steady state operation ( $\sim 4$ residence times per experimental condition) before recording each data point. Each steady state $\mathrm{CO}_{2}$ concentration was calculated from the average of $10 \mathrm{CO}_{2}$ sensor readings. All experiments were repeated 3 times.

\section{RESULTS AND DISCUSSION}

Light-Absorbing Composite Microspheres. With the adoption of the packed-bed flow reactor strategy, there were two primary considerations for the selection of the packing material, namely light absorption over the ultraviolet and visible region of the solar spectrum, and pressure drop across the flow reactor $(\Delta P)$. These characteristics were tested for four different light-absorbing material candidates, including carbon black powder (both as-received and isostatically pressed/sieved), white titanium dioxide microparticles (synthesized according to the procedure discussed in Ref. 33), batch-synthesized carbon/ $\mathrm{TiO}_{2}\left(\mathrm{C} / \mathrm{TiO}_{2}\right)$ particles, and $\mathrm{G}-\mathrm{TiO}_{2}$ composite 
microspheres. Each of the packing candidates, (I) white $\mathrm{TiO}_{2}$, (II) as received carbon black, (III) isostatically pressed carbon black, (IV) batch-synthesized $\mathrm{C} / \mathrm{TiO}_{2}$, and (V) $\mathrm{G}_{-} \mathrm{TiO}_{2}$ composite particles were characterized with scanning electron microscopy (SEM) (Figure 2A). The UV-Vis absorption spectra for each of the material candidates is presented in Figure S3. The packing materials were loaded into an FEP tube (0.04" ID, 1/16" OD), and the pressure drop was measured by flowing DI water at $100 \mu \mathrm{L} /$ min through each packed bed flow reactor using an ISCO high pressure syringe pump (Figure 2B). The pressed carbon black and batch-synthesized $\mathrm{C} / \mathrm{TiO}_{2}$ particles resulted in pressure drops greater than $175 \mathrm{psi} / \mathrm{cm}$ and ruptured reactors (Figure S4) due
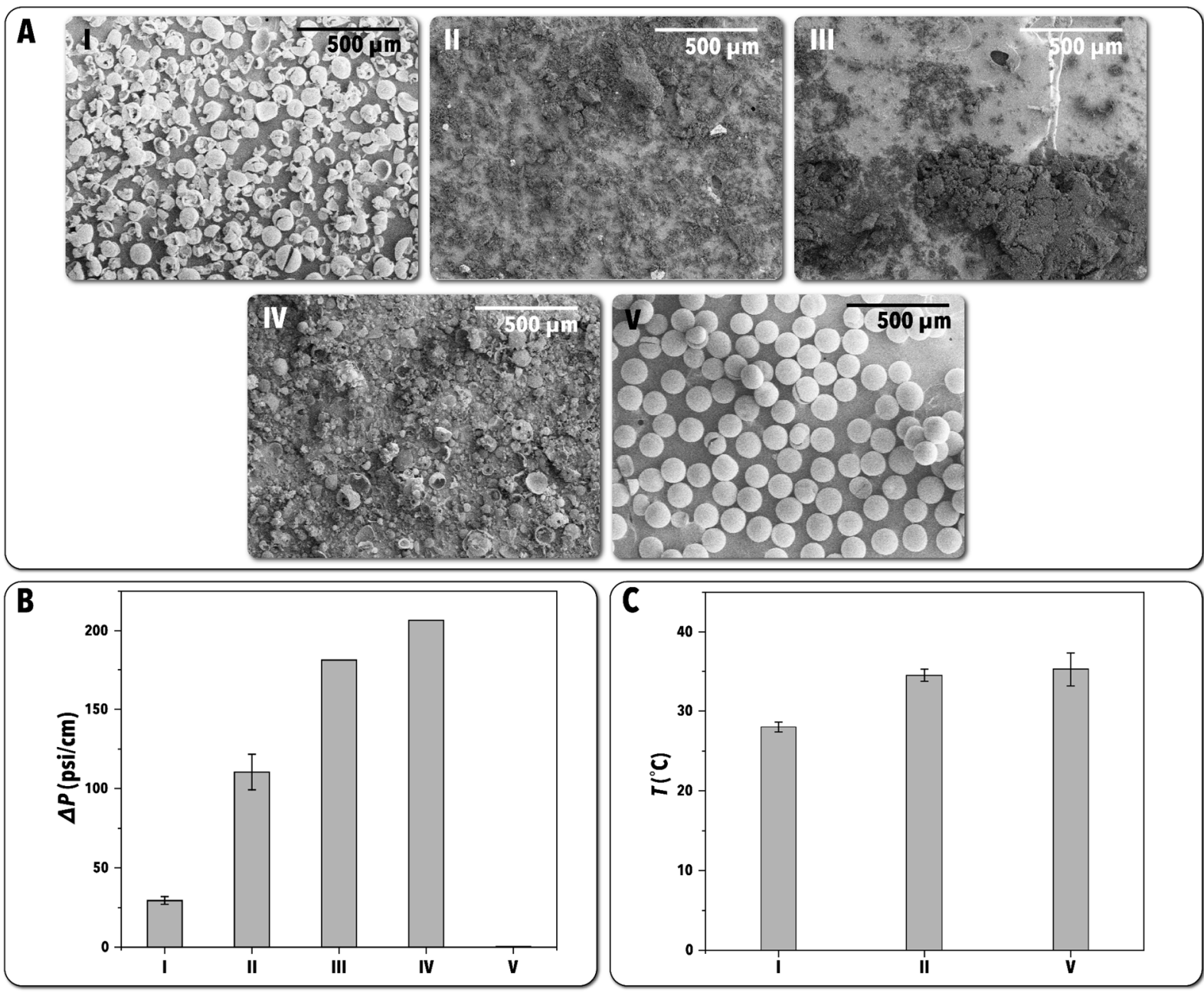

Figure 2. Characterization of the light-absorbing material candidates. (A) SEM images of the (I) flow-synthesized TiO ${ }_{2}$ microparticles, (II) as-received carbon black, (III) isostatically pressed carbon black, (IV) batch-synthesized C/TiO2, and (V) flow synthesized $\mathrm{G}_{-} \mathrm{TiO}_{2}$ particles. (B) Pressure drop measurements for packed bed flow reactors fabricated with the materials shown in panel $A$. (C) The DI water temperature leaving the packed bed flow reactors constructed using the materials shown in panel $A$ under constant illumination. 
to polydisperse particle sizes and settling in the flow reactor. Meanwhile, the flow reactor packed with the highly monodisperse $\mathrm{G}_{-}-\mathrm{TiO}_{2}$ composite particles was observed to have a relatively low pressure drop of $0.5 \mathrm{psi} / \mathrm{cm}$, due to the large average size $(120 \mu \mathrm{m})$ and monodispersity of the flow-synthesized $\mathrm{G}-\mathrm{TiO}_{2}$ microspheres.

Following the pressure drop tests, the photothermal heating of the materials that did not cause mechanical failure of the flow reactor (i.e., flow-synthesized white $\mathrm{TiO}_{2}$, as received carbon black, and $\mathrm{G}-\mathrm{TiO}_{2}$ microparticles) was studied, under the same irradiance. The packed bed flow reactors (6-cm long) were illuminated using a solar simulator (A4 Lightline, Sciencetech), and the exit DI water temperature was measured by inserting a thermocouple into the exit stream. The $\mathrm{G}_{-} \mathrm{TiO}_{2}$ and the as-received carbon black particles resulted in the greatest DI water temperature increase, reaching $35^{\circ} \mathrm{C}$ and $34.5^{\circ} \mathrm{C}$, respectively (Figure $2 \mathrm{C}$ ). As the $\mathrm{G}-\mathrm{TiO}_{2}$ composite microparticles resulted in the greatest inlet/outlet temperature difference for DI water and the lowest pressure drop across the four different materials tested, they were selected as the optimal light-absorbing material for the energy-efficient, continuous solar-desorption of $\mathrm{CO}_{2}$.

The $\mathrm{G}_{-} \mathrm{TiO}_{2}$ composite microparticles were then characterized using energy dispersive $\mathrm{x}-$ ray spectroscopy (EDS), x-ray diffraction (XRD), and x-ray photoelectron spectroscopy (XPS). Figure 3A shows a bright-field image of the flow-synthesized $\mathrm{G}_{-} \mathrm{TiO}_{2}$ composite microparticles as well as EDS maps of a single cut microparticle. The EDS maps (Figure 3A II-IV) illustrate the presence of an outer $\mathrm{TiO}_{2}$ shell surrounding a carbon core containing a smaller amount of Ti atoms. The observed core-shell structure is formed by slight hydrolysis of the titanium n-butoxide trapped at the surface of the photocured particles as they are collected in DI water, while the graphite core (containing Ti atoms from the unhydrolyzed precursor) is formed as the photocured ethoxylated trimethylolpropane triacrylate is heated sufficiently to dehydrogenate the carbons but not high 
enough to begin their oxidation. Graphite formation is also likely aided by the presence of the $\mathrm{TiO}_{2}$ shell, which inhibits oxygen diffusion to the carbon core, thus preventing oxidation. The presence of the peaks at $26.5^{\circ}$ and $55^{\circ}$ in the XRD pattern (Figure 3B) indicates the presence of graphite, while the low, broad peak at $25^{\circ}$ is indicative of the presence of anatase $\mathrm{TiO}_{2}$ in the composite microparticles. Meanwhile, the XPS spectrum (Figure 3C) possessed Ti 2p and C 1s peaks with

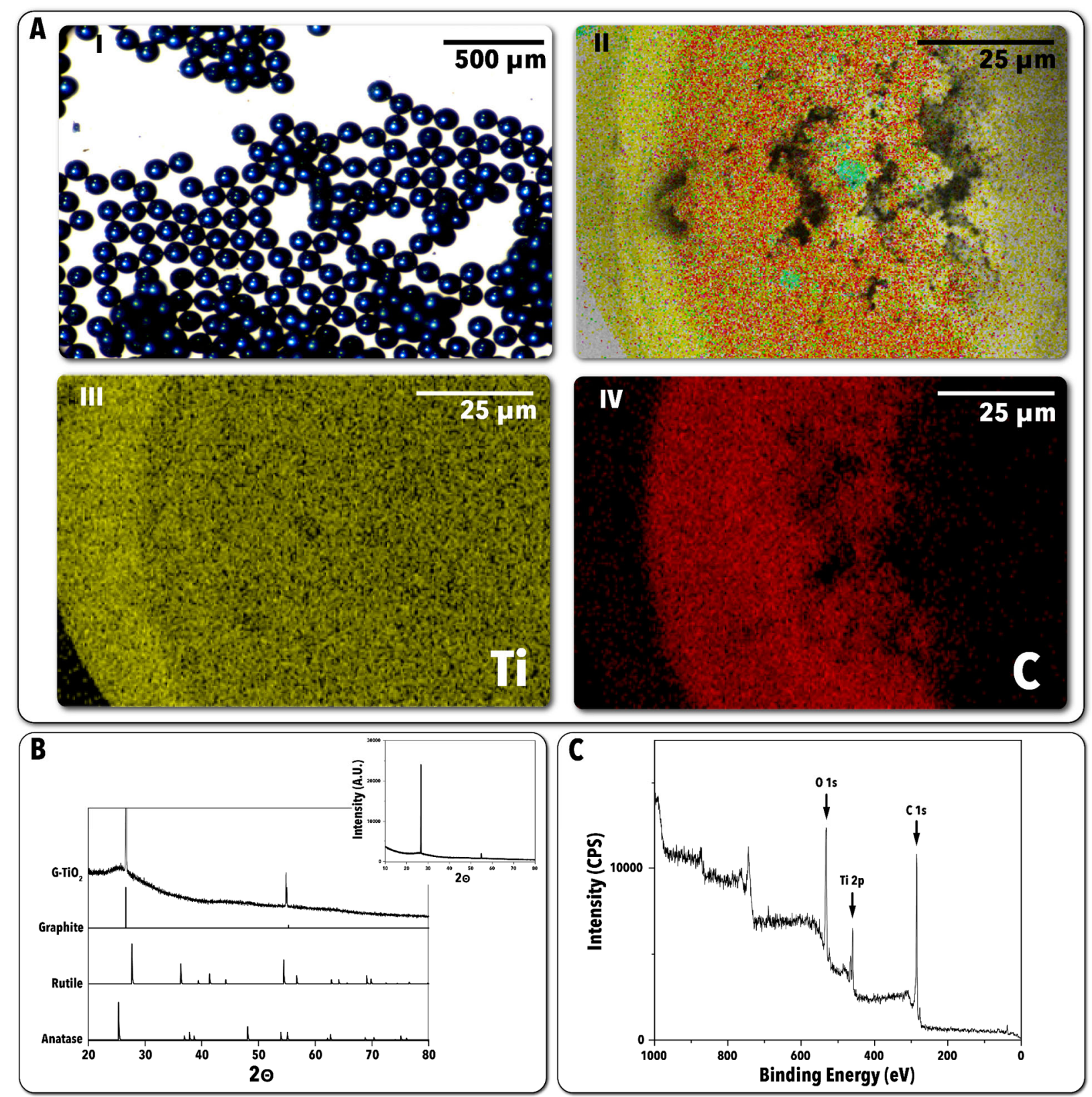

Figure 3. (A) (I) A bright-field image of the flow-synthesized $\mathrm{G}-\mathrm{TiO} \mathrm{O}_{2}$ particles. (II) EDS map of a cut $\mathrm{G}$-TiO $\mathrm{O}_{2}$ microparticle. (III) Ti and (IV) C EDS maps. (B) XRD and (C) XPS spectra of the flow-synthesized $G-\mathrm{TiO}_{2}$ microparticles. 
binding energies of $460 \mathrm{eV}$ and $285 \mathrm{eV}$, respectively. The Ti $2 \mathrm{p}$ peak is consistent with the presence of $\mathrm{TiO}_{2}$, while the $\mathrm{C}$ 1s peak indicated the presence of elemental carbon. ${ }^{39-41}$

Continuous Solar-Enabled $\mathrm{CO}_{2}$ Desorption. In the next set of experiments, the developed flow reactor packed with $\mathrm{G}_{-} \mathrm{TiO}_{2}$ composite microparticles was utilized to investigate the in-flow bulk fluid photothermal heating using a metal halide lamp. DI water was loaded into a $5 \mathrm{~mL}$ syringe and only fed through the tube-in-tube flow reactor (i.e., no preheating sections or aluminum "concentrators") illuminated by the lamp suspended at a height of $32 \mathrm{~cm}$ above the flow reactor. To conduct the temperature measurements, the needle from the exit-side needle valve was removed and a thermocouple was inserted in its place, while additional thermocouples were utilized to determine the inlet temperature of the DI water fed to the flow reactor and the external temperature under the lamp. In the first test, the effect of irradiance variation on exit bulk fluid temperature was evaluated (Figure 4A) using a liquid flow rate corresponding to a 0.5 min residence time (3.7 $\mathrm{mL} / \mathrm{h}$ ) in the illuminated tube-in-tube flow reactor segment and lamp power settings of $250 \mathrm{~W}$, $400 \mathrm{~W}$, and $600 \mathrm{~W}$. For each tested lamp power, the feed inlet temperature remained constant, while higher temperatures were observed at higher lamp powers for both the exterior temperature and the exit bulk fluid temperature (Figure 4A). Furthermore, the DI water exit temperatures were higher than the exterior temperatures. It was found that the $400 \mathrm{~W}$ lamp power resulted in an average external temperature of $28^{\circ} \mathrm{C}$ and an average DI water exit temperature of $32{ }^{\circ} \mathrm{C}$, while the temperatures measured at the $600 \mathrm{~W}$ lamp power were $37{ }^{\circ} \mathrm{C}$ and $51{ }^{\circ} \mathrm{C}$, respectively. The increased bulk fluid temperature above the ambient temperature upon increasing the irradiance (controlled by the lamp power) was a result of the photothermal heating of the packed $\mathrm{G}-\mathrm{TiO}_{2}$ particles in the flow reactor. Next, we evaluated the effect of residence time under a constant irradiance on the fluid photothermal heating in the packed bed flow reactor. The irradiance was 


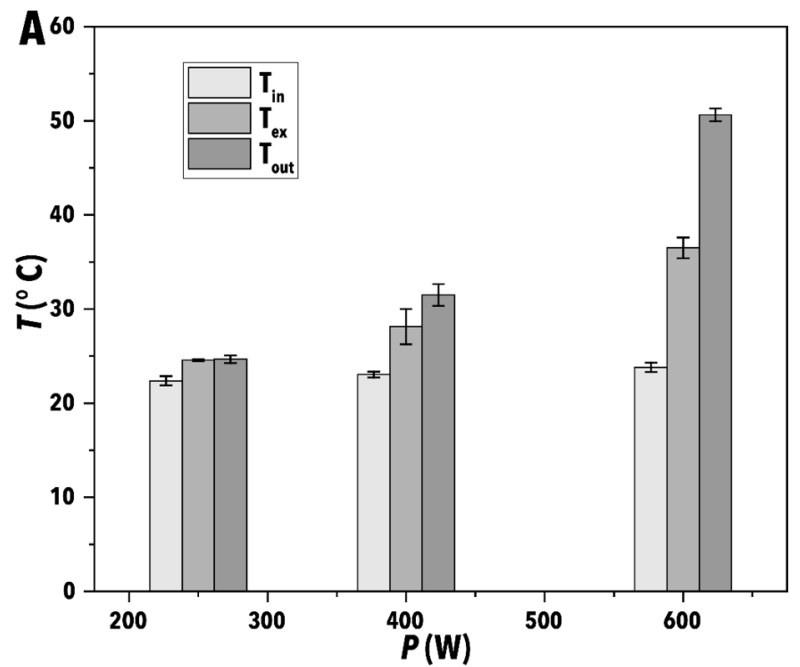

held constant (with the lamp power of $600 \mathrm{~W}$ ), while $t_{\mathrm{R}}$ was varied from $0.5 \min (3.7 \mathrm{~mL} / \mathrm{h})$ to $5 \min (0.37 \mathrm{~mL} / \mathrm{h})$ (Figure 4B). As expected,
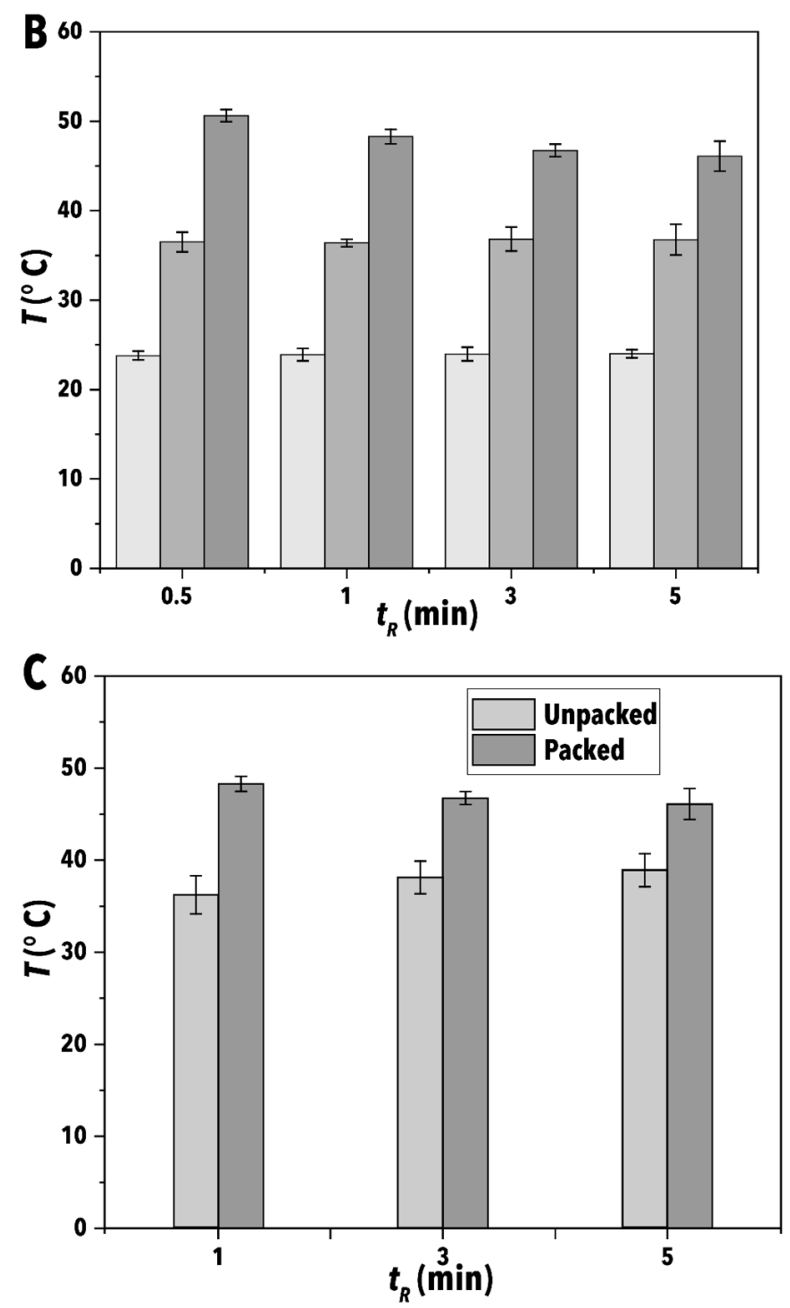

Figure 4. (A) Graph of temperature vs. lamp power for the inlet flow $\left(T_{\text {in }}\right)$, reactor exterior $\left(T_{\text {ex }}\right)$, and exit flow $\left(T_{\text {out }}\right)$ of the packed reactor. (B) Graph of temperature vs. residence time for inlet flow, reactor exterior, and exit flow of the packed reactor. (C) Control experiments for the exit flow temperature without packing by residence time at $600 \mathrm{~W}$ compared to the same conditions with packing.

the reactor inlet and external temperatures remained constant, while higher fluid exit temperatures were observed at lower residence times, contrary to expectations. However, this is explained by the presence of a "dead zone" between the illuminated flow reactor segment and the thermocouple, as the thermocouple could only be inserted as far as the PEEK frit installed to keep the packing in place (Figure S5A). The lower flow rates corresponding to higher $t_{\mathrm{R}}$ result in greater time spent in the "dead zone", where the fluid cools prior to contacting the exit thermocouple. In the next set of packed bed flow reactor characterization experiments, we conducted a control experiment with an unpacked flow reactor at a similar irradiance to the packed bed flow reactor $(600 \mathrm{~W}$ lamp power) and $32 \mathrm{~cm}$ lamp height and different residence times (Figure 4C). The measured temperatures followed the expected pattern, 
with the highest temperature, $38{ }^{\circ} \mathrm{C}$, observed at a $5 \mathrm{~min}$ residence time, and the lowest temperature, $36{ }^{\circ} \mathrm{C}$, observed at the highest flowrate (i.e., lowest residence time in the flow reactor). The difference in the observed temperature pattern (i.e., negative $T v s . t_{\mathrm{R}}$ correlation in the packed bed flow reactor, positive $T v s . t_{\mathrm{R}}$ correlation in unpacked reactor) is explained by the location of the thermocouple in the unpacked reactor, as the absence of packing materials enabled the thermocouple to be placed at the end of the illuminated section, eliminating the "dead zone." The temperatures were consistent with the previously measured external temperatures, indicating that the presence of the packing dramatically improves the in-reactor photothermal heating. It should be noted that the temperatures achieved in the illuminated region of the packed-bed flow reactor should be substantially higher than those measured, as the temperature measurements in the packed-bed flow reactor were taken at the exit valve rather than the interior of the illuminated section due to the additional packing and the frit used to keep the reactor packing in place (Figure S5B).

After it was established that the presence of the flow-synthesized $\mathrm{G}_{-} \mathrm{TiO}_{2}$ particles and illumination resulted in substantial photothermal heating of the liquid fed into the packed-bed flow reactor, a preheating section (packing of the light-absorbing microparticles in the feed tube) was incorporated and folded strips of aluminum were added under the heating segments of the flow reactor to enhance illumination from all directions. The effect of irradiance $(I)$ on the $\mathrm{CO}_{2}$ desorption efficiency $\left(E_{\mathrm{D}}=\mathrm{mol} \mathrm{CO} 2\right.$ desorbed $/ \mathrm{mol} \mathrm{CO}_{2}$ in amine $)$ was then investigated by varying I (lamp power and height) with a $\mathrm{CO}_{2}$-saturated $5 \mathrm{M}$ aqueous MEA solution at a constant residence time. Figure 5A presents the measured $I$ at different power and height combinations using a pyranometer (Tenmars TM206 Handheld Solar Power Meter). The highest $I$ was observed at the highest lamp power, as measurements of $1013 \mathrm{~W} / \mathrm{m}^{2}$ and $857 \mathrm{~W} / \mathrm{m}^{2}$ were recorded at $29 \mathrm{~cm}$ and 
$32 \mathrm{~cm}$ lamp heights, respectively. As expected, lowering the lamp power substantially decreased $I$ substantially. Figure 5B shows that $E_{\mathrm{D}}$ increased with increasing $I$. Increasing $I$ results in greater light absorption by the $\mathrm{G}-\mathrm{TiO}_{2}$ composite microparticles within the packed-bed flow reactor, and thus greater bulk fluid photothermal heating. While it was possible to further increase the irradiance by decreasing the lamp height, $\sim 1000 \mathrm{~W} / \mathrm{m}^{2}$ was selected as the maximum value to be consistent with maximum solar irradiance. Furthermore, additional experiments were completed outdoor on a sunny day $\left(31^{\circ} \mathrm{C}\right.$, approximately $\left.1000 \mathrm{~W} / \mathrm{m}^{2} I\right)$ to compare natural solar irradiation to the metal halide lamp used for the indoor screening experiments. Using a $5 \mathrm{M}$ MEA solution at a $3 \mathrm{~min}$ residence time, the solar irradiance experiment resulted in an average single-pass $\mathrm{CO}_{2}$ desorption efficiency of $22 \%$ compared to the $25 \%$ obtained using the metal halide lamp. This result indicates reasonable agreement between the experiments conducted in the lab using the metal halide lamp and the actual solar irradiance. The lower desorption under actual solar irradiation is likely attributable to slightly lower external temperatures compared to those observed with the metal halide lamp $\left(\sim 31{ }^{\circ} \mathrm{C}\right.$ vs. $\left.\sim 35^{\circ} \mathrm{C}\right)$. Additionally, we conducted control experiments
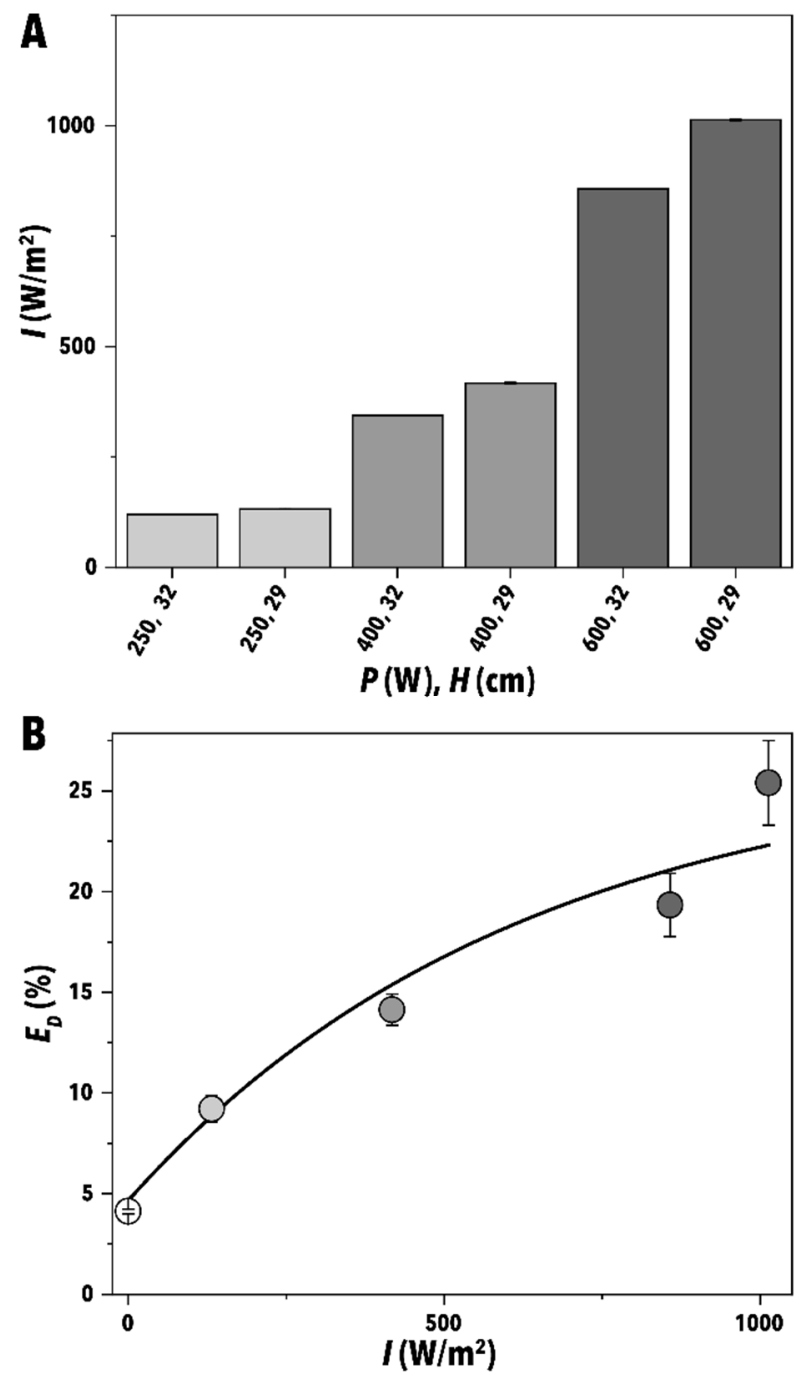

Figure 5. (A) Measured irradiance vs. lamp power and height. without packing the flow reactor at a $3 \mathrm{~min} \begin{aligned} & \text { (B) } \mathrm{CO}_{2} \text { desorption efficiency } v \text { s. irradiance at a } 5 \text { min } t_{\mathrm{R}} \text { using } \\ & 5 \mathrm{MMEA} \text {. }\end{aligned}$ 
residence time using a $5 \mathrm{M}$ MEA solution at an irradiance of $\sim 1000 \mathrm{~W} / \mathrm{m}^{2}$. The illuminated, unpacked flow reactor produced an average $\mathrm{CO}_{2}$ desorption efficiency of $9 \%$, which is attributable to the heat produced by the lamp $\left(\sim 35{ }^{\circ} \mathrm{C}\right)$ causing a small amount of $\mathrm{CO}_{2}$ desorption.

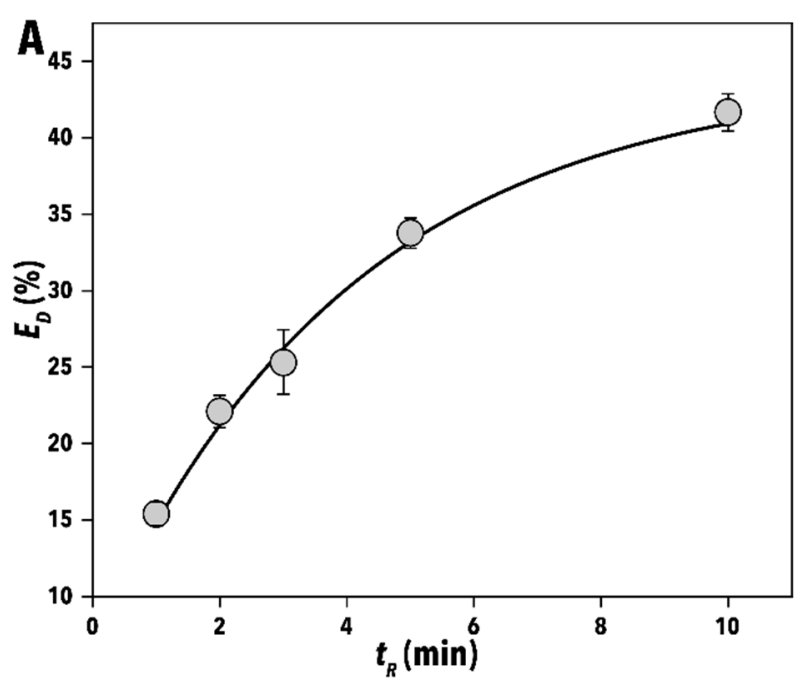

Following the determination of reasonable agreement between indoor and outdoor $\mathrm{CO}_{2}$ desorption efficiency results using the developed continuous flow reactor, in the next set of experiments we evaluated the effect of residence time, amine concentration, and amine type on the solar-enabled $\mathrm{CO}_{2}$ desorption efficiency. Figure 6A presents the effect of residence time on the solar-enabled $\mathrm{CO}_{2}$ desorption using $5 \mathrm{M}$ MEA and an irradiance of $\sim 1000 \mathrm{~W} / \mathrm{m}^{2}$. As can be seen in Figure 6A, increasing the residence time increases the measured $\mathrm{CO}_{2}$ desorption efficiency, which is expected as the aqueous amine solution spends more time in the microreactor, allowing the bulk fluid to reach higher local temperatures
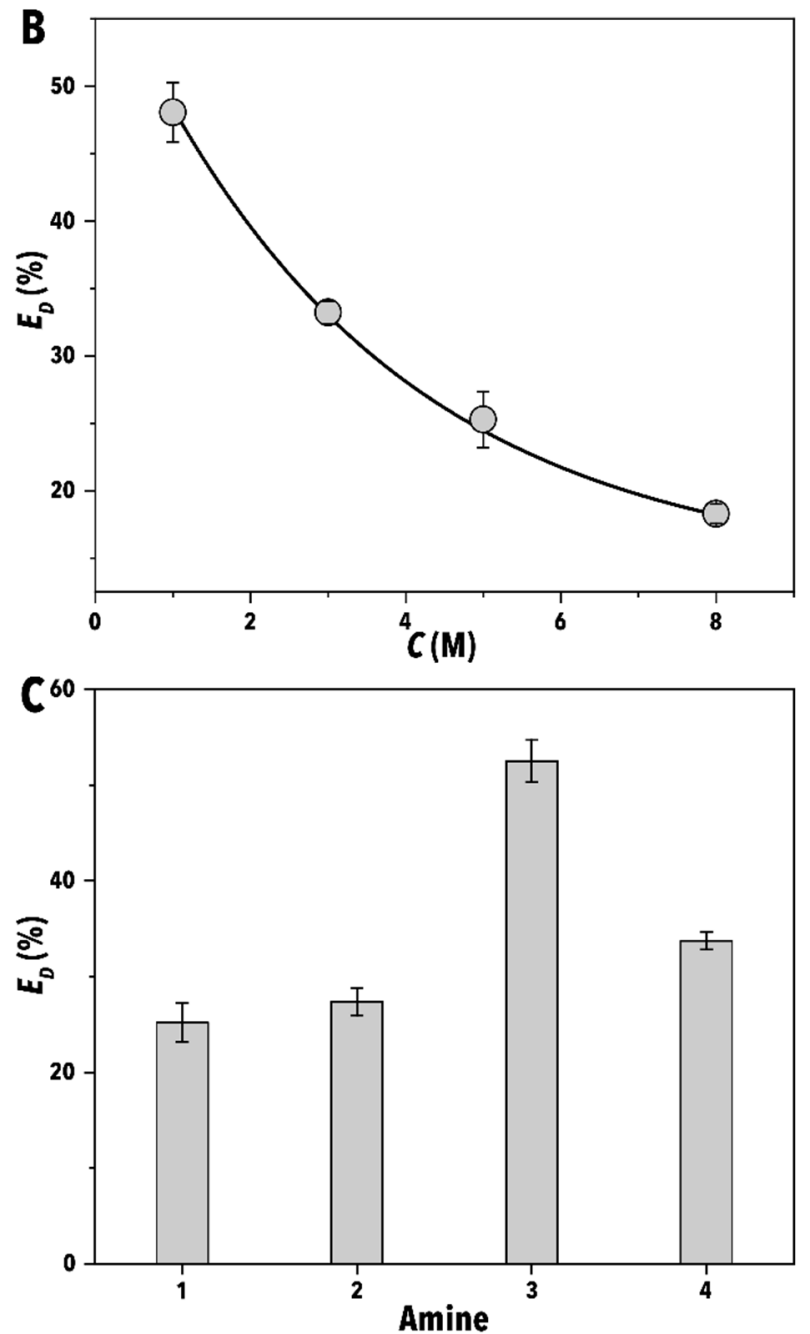

Figure 6. (A) Measured $E_{D}$ for different residence times at $I=\sim 1000 \mathrm{~W} / \mathrm{m}^{2}$, using a $5 \mathrm{MMEA}$ solution. (B) Measured $E_{D}$ for different MEA concentrations at $I=\sim 1000 \mathrm{~W} / \mathrm{m}^{2}$ and $t_{R}=3$ min. (C) Measured $E_{D}$ for various amines at $I=\sim 1000 \mathrm{~W} / \mathrm{m}^{2}$ and $t_{R}=3$ min; 1, 2, and 3 were $5 \mathrm{M}$ concentrations, 4 was $3 \mathrm{M}$. 
and desorb larger amounts of $\mathrm{CO}_{2}$. The largest single-pass $\mathrm{CO}_{2}$ desorption efficiency of MEA was obtained for a residence time of $10 \mathrm{~min}(\sim 42 \%)$. After exploring residence time effects, we explored the effect of saturated amine feed parameters on the $\mathrm{CO}_{2}$ desorption efficiency. Figure 6B shows the effect of MEA concentration $(C)$ on the $\mathrm{CO}_{2}$ solar-desorption efficiency. Decreasing $E_{D}$ was observed with increasing $C$, with the highest single-pass efficiency (48\%) obtained at $1 \mathrm{M}$ concentration. This pattern is attributable to the high heat capacity of the $\mathrm{CO}_{2}$-saturated MEA, as well as the fact that $\mathrm{CO}_{2}$ desorption is an endothermic reaction. The additional energy required to sufficiently heat the saturated amine absorbent due to the increased mixture heat capacity coupled with the greater quantity of $\mathrm{CO}_{2}$ absorbed in higher concentration MEA solutions explains the lower desorption efficiencies observed. Furthermore, it was observed that the fraction of $\mathrm{CO}_{2}$ absorbed per mole of MEA decreased as the MEA concentration increased, which may be attributable to the reaction exothermicity resulting in a lower $\mathrm{CO}_{2}$ equilibria or reduced $\mathrm{CO}_{2}$ mass transfer coefficients at higher amine concentrations. ${ }^{42}$

In order to demonstrate the versatility of the developed solar-enabled $\mathrm{CO}_{2}$ desorption strategy, in the next set of experiments we utilized the developed fluidic platform to evaluate the performance of other potential $\mathrm{CO}_{2}$ absorbers under a constant irradiance of $\sim 1000 \mathrm{~W} / \mathrm{m}^{2}$ (Figure 6C). Scheme 1 illustrates the amines utilized in this study: 1 MEA, 2 N-methyl monoethanolamine (MMEA), 3 N,N- dimethyl monoethanolamine (DMEA), and 4 piperazine (PIP). Of the tested amines, MEA demonstrated the lowest $\mathrm{CO}_{2}$ desorption efficiency in the packed-bed flow reactor, followed by MMEA
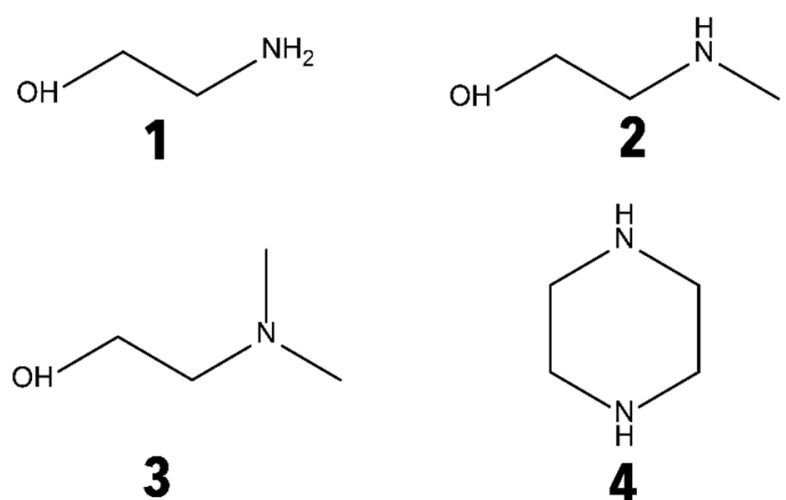

Scheme 1. Amines tested: 1 monoethanolamine (MEA), $2 \mathrm{~N}$ methyl monoethanolamine (MMEA), $3 \quad \mathrm{~N}, \mathrm{~N}$-dimethyl monoethanolamine (DMEA), 4 piperazine (PIP). 
(Figure 6C). PIP exhibited the second highest $\mathrm{CO}_{2}$ desorption efficiency (34\%) with the highest fraction of $\mathrm{CO}_{2}$ absorbed per mole (0.83), but required the use of a $3 \mathrm{M}$ solution due to solubility issues at $5 \mathrm{M}$ concentration. DMEA possessed the highest $\mathrm{CO}_{2}$ desorption efficiency (53\%) with the lowest fraction of $\mathrm{CO}_{2}$ absorption (0.22). The observed trend is explained by the degree of amine functionalization, as more energy is required to desorb $\mathrm{CO}_{2}$ from amines with fewer substituents (i.e., primary $>$ secondary $>$ tertiary). ${ }^{43}$

Dynamic Solar Irradiance. To implement a solar-driven packed-bed flow reactor strategy for energy-efficient $\mathrm{CO}_{2}$ capture and desorption processes using chemical absorbents, the system must be robust enough to deal with natural fluctuations of the solar irradiance. Therefore, we evaluated the effect of irradiance variation on the amount of $\mathrm{CO}_{2}$ desorbed in the packed-bed flow reactor by repeatedly changing the lamp height during a continuous $\mathrm{CO}_{2}$ desorption process. Figure 7A illustrates the variation in the irradiance and the corresponding changes in $\mathrm{CO}_{2}$ release caused by varying the irradiance through changing the lamp height between $29 \mathrm{~cm}$ and $32 \mathrm{~cm}$. Since $\mathrm{CO}_{2}$ production from point source applications (e.g., power plants) will remain relatively constant, it is necessary to ensure that other process parameters may be tuned to maintain a constant $\mathrm{CO}_{2}$ desorption efficiency, especially if
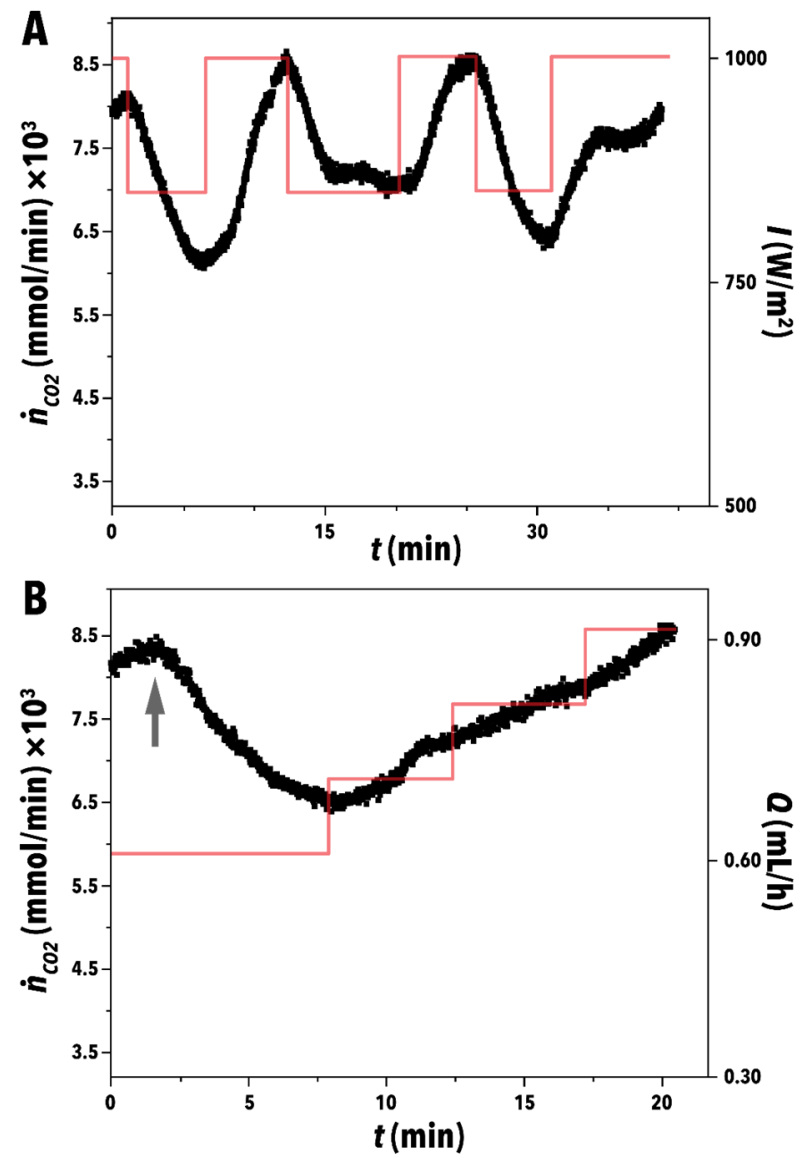

Figure 7. (A) Fluctuations in $\mathrm{CO}_{2}$ release caused by variation in I between $\sim 1000 \mathrm{~W} / \mathrm{m}^{2}$ and $\sim 860 \mathrm{~W} / \mathrm{m}^{2}$. (B) Proof-of-concept for feedforward control based on irradiance. $\mathrm{CO}_{2}$ release is combined with a controller for real-time control returned to its original value by varying the aqueous amine feed flow rate. 
based on measured irradiance and ambient temperature. Figure 7B shows the decrease in $\mathrm{CO}_{2}$ release caused by the change in the irradiance from $\sim 1000 \mathrm{~W} / \mathrm{m}^{2}$ to $\sim 860 \mathrm{~W} / \mathrm{m}^{2}$ at the point indicated by the arrow. After $7.5 \mathrm{~min}$, the flow rate was increased in stepwise increments of 0.1 $\mathrm{mL} / \mathrm{h}$ to increase the total amount of $\mathrm{CO}_{2}$ released back to its initial value. This proof-of-concept result demonstrates the possible implementation of a real-time controller to maintain constant $\mathrm{CO}_{2}$ desorption throughput a day using the packed-bed solar desorber. ${ }^{44}$

Next, we studied stability of maximum $\mathrm{CO}_{2}$ desorption within the developed continuous packed-bed flow reactor for PIP, due to its comparatively high $\mathrm{CO}_{2}$ absorption and superior desorption efficiency. Figure 8 shows the stability test conducted using 1 M PIP (0.934 mol $\mathrm{CO}_{2} / \mathrm{mol}$ PIP) over the course of $800 \mathrm{~min}$ at a constant $10 \mathrm{~min}$ residence time and an irradiance of $\sim 1000 \mathrm{~W} / \mathrm{m}^{2}$. Under these conditions, the measured $E_{\mathrm{D}}$ remained relatively stable, at an average single-pass efficiency of $64 \%$. However, it is apparent that some instability is present, as seen with the oscillation between $\sim 55 \%$ and $\sim 75 \%$, which may be attributable to flow inconsistencies caused by the syringe pump or the formation of $\mathrm{CO}_{2}$ bubbles in the preheating section. As the tests were conducted using a 10 min residence time with a single-pass through the flow reactor, it is conceivable that the overall $E_{D}$ could be increased further by using a longer residence time and/or recycling the partially regenerated absorbent through the same packed-bed flow reactor.

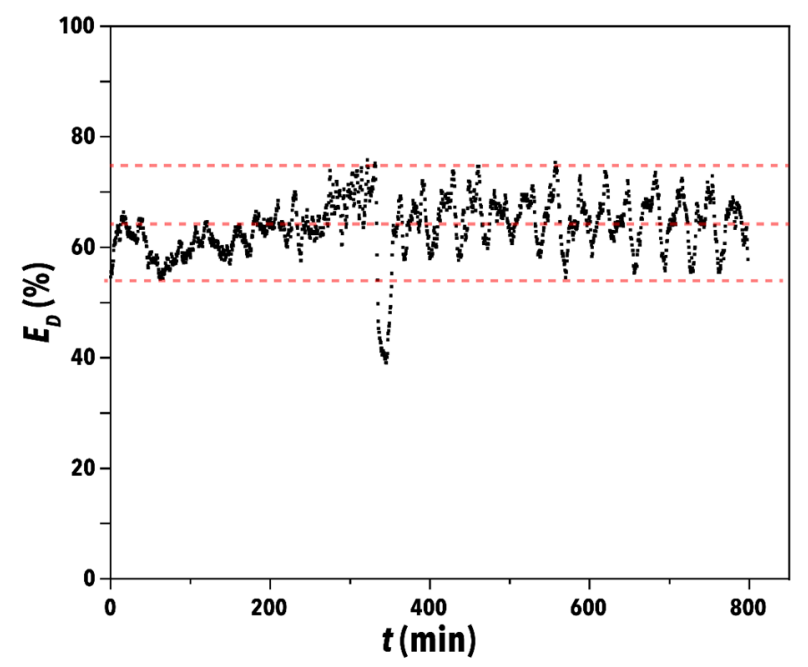

Figure 8. Measured $E_{D}$ stability tests at 10 min residence time under $I=\sim 1000 \mathrm{~W} / \mathrm{m}^{2}$, and $1 \mathrm{M}$ concentration of PIP. 


\section{CONCLUSION}

In conclusion, we demonstrated the design and utilization of a continuous flow strategy equipped with a packed-bed flow reactor to enable rapid, energy-efficient in operando solar desorption and recovery of $\mathrm{CO}_{2}$ from aqueous amines. Among different tested light-absorbing materials, including standard $\mathrm{TiO}_{2}$ microparticles, $\mathrm{G}-\mathrm{TiO}_{2}$ composite microparticles, batchsynthesized $\mathrm{C} / \mathrm{TiO}_{2}$ microparticles, as-received carbon black, and isostatically pressed and sieved carbon black, the composite microspheres demonstrated to be the most effective material candidate for continuous photothermal fluid heating with minimal pressure drop across the flow reactor (i.e., low capital cost). $\mathrm{CO}_{2}$ desorption efficiency was then tested as a function of irradiance and aqueous amine residence time, as well as amine concentration and structure, where it was demonstrated that the desorption efficiency increased with higher irradiance and residence time, lower concentration, and the presence of more electron-donating groups bonded to the nitrogen. The potential for integration of a real-time controller into the solar-enabled $\mathrm{CO}_{2}$ desorption process was also demonstrated, enabling the amount of solar-desorbed $\mathrm{CO}_{2}$ by the continuous flow reactor to remain constant with dynamic solar irradiance. Finally, maximum desorption efficiency stability tests were conducted using piperazine, where a maximum average single-pass desorption efficiency of $64 \%$ was achieved for a residence time of $10 \mathrm{~min}$, with the opportunity for higher desorption with increased residence time and/or absorbent recycling. The results of this work demonstrated that continuous flow reactors packed with highly monodisperse, light-absorbing microparticles may be effectively implemented to efficiently desorb $\mathrm{CO}_{2}$ from aqueous amine absorbents with minimal energy input. Additional studies are needed to scale up the developed technique for utilization in industrial scale $\mathrm{CO}_{2}$ capture. 


\title{
ASSOCIATED CONTENT
}

Supporting Information. The Supporting Information is available free of charge at DOI:

Images of the packed bed microreactor with and without the outer tube, emission spectrum of the metal halide lamp used to carry out the desorption experiments, image of a packed bed ruptured during the pressure drop tests, and UV-Vis spectra of the various packing candidates characterized in this work.

\section{AUTHOR INFORMATION}

\section{Corresponding Author}

*Co-Corresponding Authors

Email: abolhasani@ncsu.edu, samuel.marre@icmcb.cnrs.fr

Website: abolhasanilab.com, sites.google.com/site/samuelmarre/

\author{
Author Contributions \\ The manuscript was written through contributions of all authors. All authors have given approval \\ to the final version of the manuscript.
}

\section{ACKNOWLEDGMENT}

This work was supported with funding from the European Research Council (ERC) under the European Union's Horizon 2020 research and innovation program (Grant Agreement No. 725100, project BigMAC). Characterization was performed in part at the Analytical Instrumentation Facility (AIF) at North Carolina State University, which is supported by the State of North Carolina and the National Science Foundation (award number ECCS-2025064). The AIF is a member of 
the North Carolina Research Triangle Nanotechnology Network (RTNN), a site in the National Nanotechnology Coordinated Infrastructure (NNCI). Z. S. C. would also like to acknowledge the Fulbright Program and the Franco-American Fulbright Commission for their financial support.

\section{REFERENCES}

(1) Cao, L.; Bala, G.; Caldeira, K.; Nemani, R.; Ban-Weiss, G. Importance of Carbon Dioxide Physiological Forcing to Future Climate Change. Proc. Natl. Acad. Sci. U. S. A. 2010, 107 (21), 9513-9518. https://doi.org/10.1073/pnas.0913000107.

(2) Lacis, A. A.; Schmidt, G. A.; Rind, D.; Ruedy, R. A. Atmospheric $\mathrm{CO}_{2}$ : Principal Control Knob Governing Earth’s Temperature. Science (80-. ). 2017, 330, 356-359.

(3) Jackson, R. B.; Le Quéré, C.; Andrew, R. M.; Canadell, J. G.; Korsbakken, J. I.; Liu, Z.; Peters, G. P.; Zheng, B. Global Energy Growth Is Outpacing Decarbonization. Environ. Res. Lett. 2018, 13 (12), 120401.

(4) Peters, G. P.; Andrew, R. M.; Canadell, J. G.; Friedlingstein, P.; Jackson, R. B.; Korsbakken, J. I.; Le Quéré, C.; Peregon, A. Carbon Dioxide Emissions Continue to Grow amidst Slowly Emerging Climate Policies. Nat. Clim. Chang. 2020, 10 (1), 3-6.

(5) Quéré, C.; Andrew, R.; Friedlingstein, P.; Sitch, S.; Hauck, J.; Pongratz, J.; Pickers, P.; Ivar Korsbakken, J.; Peters, G.; Canadell, J. Global Carbon Budget 2018. Earth Syst. Sci. Data 2018, 10 (4), 2141-2194.

(6) Mac Dowell, N.; Fennell, P. S.; Shah, N.; Maitland, G. C. The Role of $\mathrm{CO}_{2}$ Capture and Utilization in Mitigating Climate Change. Nat. Clim. Chang. 2017, 7 (4), 243-249.

(7) Zhengshan, J. Y.; Carpenter, J. V; Holman, Z. C. Techno-Economic Viability of SiliconBased Tandem Photovoltaic Modules in the United States. Nat. Energy 2018, 3 (9), 747753.

(8) Voskian, S.; Hatton, T. A. Faradaic Electro-Swing Reactive Adsorption for $\mathrm{CO}_{2} \mathrm{Capture}$ 
Energy Environ. Sci. 2019, 12 (12), 3530-3547. https://doi.org/10.1039/c9ee02412c.

(9) Thompson, J. A.; Brunelli, N. A.; Lively, R. P.; Johnson, J. R.; Jones, C. W.; Nair, S. Tunable $\mathrm{CO}_{2}$ Adsorbents by Mixed-Linker Synthesis and Postsynthetic Modification of Zeolitic Imidazolate Frameworks. J. Phys. Chem. C 2013, 117 (16), 8198-8207.

(10) Chakraborty, A. K.; Astarita, G.; Bischoff, K. B. $\mathrm{CO}_{2}$ Absorption in Aqueous Solutions of Hindered Amines. Chem. Eng. Sci. 1986, 41 (4), 997-1003.

(11) Peters, L.; Hussain, A.; Follmann, M.; Melin, T.; Hägg, M.-B. $\mathrm{CO}_{2}$ Removal from Natural Gas by Employing Amine Absorption and Membrane Technology-A Technical and Economical Analysis. Chem. Eng. J. 2011, 172 (2-3), 952-960.

(12) Thompson, J. A.; Vaughn, J. T.; Brunelli, N. A.; Koros, W. J.; Jones, C. W.; Nair, S. MixedLinker Zeolitic Imidazolate Framework Mixed-Matrix Membranes for Aggressive $\mathrm{CO}_{2}$ Separation from Natural Gas. Microporous mesoporous Mater. 2014, 192, 43-51.

(13) Lively, R. P.; Dose, M. E.; Xu, L.; Vaughn, J. T.; Johnson, J. R.; Thompson, J. A.; Zhang, K.; Lydon, M. E.; Lee, J.-S.; Liu, L. A High-Flux Polyimide Hollow Fiber Membrane to Minimize Footprint and Energy Penalty for $\mathrm{CO}_{2}$ Recovery from Flue Gas. J. Memb. Sci. 2012, 423, 302-313.

(14) Mangalapally, H. P.; Notz, R.; Hoch, S.; Asprion, N.; Sieder, G.; Garcia, H.; Hasse, H. Pilot Plant Experimental Studies of Post Combustion $\mathrm{CO}_{2}$ Capture by Reactive Absorption with MEA and New Solvents. Energy Procedia 2009, 1 (1), 963-970.

(15) Yeh, J. T.; Pennline, H. W.; Resnik, K. P. Study of $\mathrm{CO}_{2}$ Absorption and Desorption in a Packed Column. Energy \& fuels 2001, 15 (2), 274-278.

(16) Le Moullec, Y.; Neveux, T.; Al Azki, A.; Chikukwa, A.; Hoff, K. A. Process Modifications for Solvent-Based Post-Combustion $\mathrm{CO}_{2}$ Capture. Int. J. Greenh. Gas Control 2014, 31, 96-112.

(17) Nguyen, D. T.; Truong, R.; Lee, R.; Goetz, S. A.; Esser-Kahn, A. P. Photothermal Release of $\mathrm{CO}_{2}$ from Capture Solutions Using Nanoparticles. Energy Environ. Sci. 2014, 7 (8), 
2603-2607. https://doi.org/10.1039/c4ee01047g.

(18) Sambiagio, C.; Noël, T. Flow Photochemistry: Shine Some Light on Those Tubes! Trends Chem. 2020, 2 (2), 92-106. https://doi.org/10.1016/j.trechm.2019.09.003.

(19) Cambié, D.; Bottecchia, C.; Straathof, N. J. W.; Hessel, V.; Noel, T. Applications of Continuous-Flow Photochemistry in Organic Synthesis, Material Science, and Water Treatment. Chem. Rev. 2016, 116 (17), 10276-10341.

(20) Günther, A.; Jensen, K. F. Multiphase Microfluidics: From Flow Characteristics to Chemical and Materials Synthesis. Lab Chip 2006, 6 (12), 1487-1503. https://doi.org/10.1039/B609851G.

(21) Whitesides, G. M. The Origins and the Future of Microfluidics. Nature 2006, 442 (7101), 368-373. https://doi.org/10.1038/nature05058.

(22) Abolhasani, M.; Kumacheva, E.; Günther, A. Peclet Number Dependence of Mass Transfer in Microscale Segmented Gas-Liquid Flow. Ind. Eng. Chem. Res. 2015, 54 (36), 90469051.

(23) Abolhasani, M.; Günther, A.; Kumacheva, E. Microfluidic Studies of Carbon Dioxide. Angew. Chemie Int. Ed. 2014, 53 (31), 7992-8002.

(24) Abolhasani, M.; Singh, M.; Kumacheva, E.; Günther, A. Automated Microfluidic Platform for Studies of Carbon Dioxide Dissolution and Solubility in Physical Solvents. Lab Chip 2012, 12 (9), 1611-1618.

(25) Lefortier, S. G. R.; Hamersma, P. J.; Bardow, A.; Kreutzer, M. T. Rapid Microfluidic Screening of $\mathrm{CO}_{2}$ Solubility and Diffusion in Pure and Mixed Solvents. Lab Chip 2012, 12 (18), 3387-3391.

(26) Fransen, S.; Kuhn, S. A Model-Based Technique for the Determination of Interfacial Fluxes in Gas-Liquid Flows in Capillaries. React. Chem. Eng. 2016, 1 (3), 288-299.

(27) Han, S.; Raghuvanshi, K.; Abolhasani, M. Accelerated Material-Efficient Investigation of 
Switchable Hydrophilicity Solvents for Energy-Efficient Solvent Recovery. ACS Sustain. Chem. Eng. 2020, 8 (8), 3347-3356. https://doi.org/10.1021/acssuschemeng.9b07304.

(28) Voicu, D.; Abolhasani, M.; Choueiri, R.; Lestari, G.; Seiler, C.; Menard, G.; Greener, J.; Guenther, A.; Stephan, D. W.; Kumacheva, E. Microfluidic Studies of $\mathrm{CO}_{2}$ Sequestration by Frustrated Lewis Pairs. J. Am. Chem. Soc. 2014, 136 (10), 3875-3880.

(29) Sun, R.; Cubaud, T. Dissolution of Carbon Dioxide Bubbles and Microfluidic Multiphase Flows. Lab Chip 2011, 11 (17), 2924-2928.

(30) Liu, N.; Aymonier, C.; Lecoutre, C.; Garrabos, Y.; Marre, S. Microfluidic Approach for Studying CO2 Solubility in Water and Brine Using Confocal Raman Spectroscopy. Chem. Phys. Lett. 2012, 551, 139-143.

(31) Marre, S.; Aymonier, C.; Subra, P.; Mignard, E. Dripping to Jetting Transitions Observed from Supercritical Fluid in Liquid Microcoflows. Appl. Phys. Lett. 2009, 95 (13), 134105.

(32) Bennett, J. A.; Campbell, Z. S.; Abolhasani, M. Role of Continuous Flow Processes in Green Manufacturing of Pharmaceuticals and Specialty Chemicals. Curr. Opin. Chem. Eng. 2019, 26, 9-19. https://doi.org/10.1016/j.coche.2019.07.007.

(33) Hartman, R. L.; McMullen, J. P.; Jensen, K. F. Deciding Whether to Go with the Flow: Evaluating the Merits of Flow Reactors for Synthesis. Angew. Chem. Int. Ed. 2011, 50 (33), 7502-7519. https://doi.org/10.1002/anie.201004637.

(34) Brzozowski, M.; O’Brien, M.; Ley, S. V.; Polyzos, A. Flow Chemistry: Intelligent Processing of Gas-Liquid Transformations Using a Tube-in-Tube Reactor. Acc. Chem. Res. 2015, 48 (2), 349-362. https://doi.org/10.1021/ar500359m.

(35) Campbell, Z. S.; Parker, M.; Bennett, A.; Yusuf, S.; Al-Rashdi, A. K.; Lustik, J.; Li, F.; Abolhasani, M. Continuous Synthesis of Monodisperse Yolk - Shell Titania Microspheres. Chem. Mater. 2018, 30 (24), 8948-8958. https://doi.org/10.1021/acs.chemmater.8b04349.

(36) Campbell, Z. S.; Jackson, D.; Lustik, J.; Al-Rashdi, A. K.; Bennett, J. A.; Li, F.; Abolhasani, M. Continuous Flow Synthesis of Phase Transition-Resistant Titania Microparticles with 
Tunable Morphologies. RSC Adv. 2020, $10 \quad$ (14), 8340-8347. https://doi.org/10.1039/d0ra01442g.

(37) Bennett, J. A.; Kristof, A. J.; Vasudevan, V.; Genzer, J.; Srogl, J.; Abolhasani, M. Microfluidic Synthesis of Elastomeric Microparticles: A Case Study in Catalysis of Palladium-Mediated Cross-Coupling. AIChE J. 2018, $64 \quad$ (8), 3188-3197. https://doi.org/10.1002/aic.16119.

(38) Bennett, J. A.; Campbell, Z. S.; Abolhasani, M. Continuous Synthesis of Elastomeric Macroporous Microbeads. React. Chem. Eng. 2019, 4 (2), 254-260. https://doi.org/10.1039/c8re00189h.

(39) Yu, X.; Zhang, Y.; Cheng, X. Preparation and Photoelectrochemical Performance of Expanded Graphite/TiO2 Composite. Electrochim. Acta 2014, 137, 668-675.

(40) Li, D.; Jia, J.; Zhang, Y.; Wang, N.; Guo, X.; Yu, X. Preparation and Characterization of Nano-Graphite/TiO2 Composite Photoelectrode for Photoelectrocatalytic Degradation of Hazardous Pollutant. J. Hazard. Mater. 2016, 315, 1-10.

(41) Jiang, T.; Tao, Z.; Ji, M.; Zhao, Q.; Fu, X.; Yin, H. Preparation and Photocatalytic Property of TiO2-Graphite Oxide Intercalated Composite. Catal. Commun. 2012, 28, 47-51.

(42) Conway, W.; Bruggink, S.; Beyad, Y.; Luo, W.; Melián-Cabrera, I.; Puxty, G.; Feron, P. $\mathrm{CO} 2$ Absorption into Aqueous Amine Blended Solutions Containing Monoethanolamine (MEA), N, N-Dimethylethanolamine (DMEA), N, N-Diethylethanolamine (DEEA) and 2Amino-2-Methyl-1-Propanol (AMP) for Post-Combustion Capture Processes. Chem. Eng. Sci. 2015, 126, 446-454.

(43) Ko, Y. G.; Shin, S. S.; Choi, U. S. Primary, Secondary, and Tertiary Amines for CO2 Capture: Designing for Mesoporous $\mathrm{CO}_{2}$ Adsorbents. J. Colloid Interface Sci. 2011, 361 (2), 594-602. https://doi.org/10.1016/j.jcis.2011.03.045.

(44) Zhao, F.; Cambié, D.; Hessel, V.; Debije, M. G.; Noël, T. Real-Time Reaction Control for Solar Production of Chemicals under Fluctuating Irradiance. Green Chem. 2018, 20 (11), 2459-2464. 
